\title{
The effects of alcohol concentration on schedule-induced alcohol drinking
}

\author{
J. F. SCHROT, T. D. HAWKINS, and S. H. GITHENS \\ Division of Neuropsychiatry \\ Walter Reed Army Institute of Research, Washington, D.C. 20012
}

Rats were made polydipsic for water by the free delivery of food pellets on a fixed-time 1-min schedule. Alcohol concentrations of $2.5 \%, 5.0 \%, 7.5 \%$, and $10 \%$ were then substituted for the water. An inverse relationship between fluid consumption and alcohol concentration was observed; however, the function relating grams of absolute alcohol consumed to concentration increased monotonically.

Lester (1961) was the first investigator to demonstrate adjunctive alcohol ingestion by rats responding on a VI 55-sec food schedule. These rats, drinking a $5.6 \%(\mathrm{w} / \mathrm{v})$ ethanol solution, ingested an average of $1.7 \mathrm{~g}$ of absolute alcohol, or $29.7 \mathrm{~g}$ of solution, during $3-h$ sessions. In the same study, Lester (1961) also reported preliminary observations of drinking at levels of 2 to $3 \mathrm{~g}$ of solution per hour, when either the operant contingency on pellet delivery was eliminated or the nature of the schedule was changed from aperiodic to periodic.

Everett \& King (1970) studied the relationship between fluid consumption and alcohol concentration, using rats as Ss. Their procedure consisted of delivering 100 pellets per session to rats on a variable time (VT) 1-min schedule, a procedure which eliminates the response contingency on pellet delivery. Concurrently, alcohol concentrations ranging from $0 \%$ to $\mathbf{5 \%}$ were continuously available. These investigators found an increasing monotonic function relating the amount of absolute alcohol ingested to concentration.

In a further extension of Lester's (1961) finding, Hawkins et al (1970) exposed rats to a fixed time (FT) 1-min schedule in which 100 pellets per session were freely delivered while the animal had unlimited access to a $5 \%(v / v)$ alcohol solution. These results, as well as those of Everett \& King (1970), confirmed Lester's (1961) finding of large quantities of alcohol ingested by rats while receiving small portions of food on certain behavioral schedules. In addition, the studies of Everett \& King (1970) and Hawkins et al (1970) demonstrate that large quantities of alcohol solution will be consumed by rats in the absence of a specified dependency between an operant response and food delivery, regardless of whether the schedule is periodic or aperiodic in nature.

The present study is a systematic replication of Lester (1961), Everett \&
King (1970), and Hawkins et al (1970). The alcohol concentration curve reported by Everett \& King (1970), which ranged from $0 \%$ to $5 \%$, was extended to include values at $0 \%$, $2.5 \%, 5 \%, 7.5 \%$, and $10 \%(\mathrm{v} / \mathrm{v})$. The food schedule employed was fixed time (FT) $1 \mathrm{~min}$, replicating the schedule conditions employed by Hawkins et al (1970), working with the $5 \%(\mathrm{v} / \mathrm{v})$ concentration, and extending the VI and VT schedules used by Lester (1961) and Everett \& King (1970).

METHOD AND PROCEDURE

Two adult male Wistar rats from the Walter Reed colony, designated 251 and 264 , served as Ss. The Ss were reduced from 350 to $250 \mathrm{~g}$ and held at the latter body weight for the duration of the experiment. Throughout the study, water was available ad lib in the home cage. Both Ss had extensive histories of adjunctive water drinking on an FT 1-min schedule during a previous study in this laboratory.

The apparatus consisted of a standard rat chamber, containing a feeder cup and drinking tube, mounted approximately 2 in. apart on the front wall. A pellet dispenser was located adjacent to the chamber, and a calibrated reservoir was attached to the ouside front wall. The experimental chamber was housed in a larger plywood box containing a light bulb and a blower providing air circulation. The plywood box was located in a soundproof temperature-controlled room along with a white-noise generator.

A drinkometer attached to the drinking tube and grounded to the grid floor of the chamber recorded each contact with the water tube made by $S$. These contacts were recorded on a mechanical counter and a cumulative recorder. The programming circuitry was composed of solid-state modules located outside the experimental room.

The alcohol concentrations were mixed on a volume/volume basis, e.g., a $10 \%$ solution consisted of $100 \mathrm{ml}$ of $95 \%$ ethanol in $1,000 \mathrm{ml}$ of solution.
During all of the daily sessions, the Ss received 100 45-mg Noyes pellets delivered, independently of their behavior, by an FT 1-min schedule. Additionally, fluid, consisting of either water or ethanol in various concentrations ranging from $2.5 \%$ to $10 \%$, was continuously available from the drinking tube. The fluid level in the calibrated reservoir was recorded at the beginning and end of each session. The sequence and duration of the fluid conditions are presented in Table 1.

\section{RESULTS}

The results indicate an inverse relationship between the level of fluid intake and the concentration of the alcohol solution. However, the function relating absolute alcohol ingestion to concentration is monotonically increasing, with the lowest amount of ethanol ingested at the $2.5 \%$ concentration and the highest amount at $10 \%$. These relationships are depicted in Fig. 1.

Of the two determinations at the $10 \%$ concentration in Fig. 1 , the lower points represent values obtained during the initial 20-day block. The data points for the water and initial $10 \%$ conditions are medians derived from the last 10 sessions in each condition. The data points for the remaining conditions are medians computed for the entire block of 10 sessions.

The amount of fluid consumed during the water condition is at least the equivalent of levels reported by investigators of schedule-induced polydipsia (Falk, 1969; Hawkins et al, 1970), employing a variety of free and response-contingent fixed 1-min schedules. For instance, Falk (1969) reports water intake of about $40 \mathrm{ml}$ per session in rats responding on an FI 1 -min food schedule and receiving 180 food deliveries per session. Hawkins et al (1970) observed session water drinking of approximately $60 \mathrm{ml}$ when 100 pellets per session were delivered to rats on an FT 1-min schedule. The water values obtained in this study were $62 \mathrm{ml}$ for $\mathrm{S} 264$ and $73 \mathrm{ml}$ for S 251.

Table 1 Fluid Conditions in Sequence

\begin{tabular}{cc}
$\begin{array}{c}\text { Alcohol } \\
\text { Concentration } \\
\text { (Percent) }\end{array}$ & $\begin{array}{c}\text { Number } \\
\text { of } \\
\text { Sessions }\end{array}$ \\
\hline 0.0 & 20 \\
10.0 & 20 \\
2.5 & 10 \\
5.0 & 10 \\
7.5 & 10 \\
10.0 & 10 \\
\hline
\end{tabular}




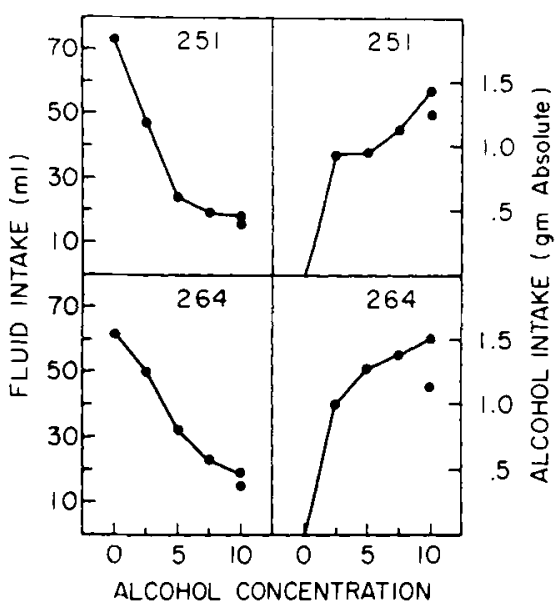

Fig. 1. Total fluid intake and grams of ethanol consumed as a function of alcohol concentration.

Coincident with the addition of increasing quantities of ethanol in the fluid, drinking levels for both rats declined monotonically. S 251 drank $47 \mathrm{ml}$ per session of the $2.5 \%$ ethanol solution, but consumed only $18 \mathrm{ml}$ per session of the $10 \%$ solution during the second, and highest, determination at that condition. S 264 , correspondingly, drank $50 \mathrm{ml}$ per session of $2.5 \%$ and $19 \mathrm{ml}$ per session of the $10 \%$ ethanol solution. However, the values obtained for absolute alcohol ingested at each condition rose monotonically as ethanol concentration increased. S251 consumed $.92 \mathrm{~g}$ per session of absolute alcohol at the $2.5 \%$ concentration and $1.43 \mathrm{~g}$ per session during the repeat $10 \%$ condition. Similarly, S264 consumed $1.0 \mathrm{~g}$ per session during $2.5 \%$ and $1.5 \mathrm{~g}$ per session with the $10 \%$ concentration.

An analysis of the individual lick records revealed that the bulk of the alcohol solution drinking took place during the first 20-30 pellet presentations. The effect was more pronounced as the concentrations increased. Both Ss exhibited short drinks (5 to $15 \mathrm{sec}$ ) scattered throughout the session, together with a few long drinks (45 to $60 \mathrm{sec}$ ) at the beginning of the session when the concentration was $2.5 \%$. As the concentrations increased through $5 \%$, $7.5 \%$, and $10 \%$, the drinking correspondingly became compressed into the early portions of the session.
In addition, the frequent short drinks disappeared, to be replaced by a comparatively small number of long drinks (10 to 15 ) occurring during the earliest portion of the session. Drinking during the water condition was characterized by drinks of approximately 20 to $30 \mathrm{sec}$ occurring after $90 \%$ or more of the pellets, a pattern resulting in the high ingestion levels depicted in Fig. 1.

The primary difference between drinking during the water and alcohol conditions, as revealed by the cumulative lick records, was the temporal distribution of drinking. During the water condition, drinks of comparable length were observed throughout the session, occurring after almost every pellet delivery. With the addition of ethanol, however, the number of drinks declined, their duration tended to increase, and they became compressed into the earliest stages of the session.

\section{DISCUSSION}

The functions depicted in Fig. 1 describing the relationships between concentration, fluid intake, and absolute alcohol intake are in agreement with results reported previously by Everett \& King (1970).

These investigators reported an inverse relationship between fluid consumption and concentration, and a monotonically increasing function relating absolute alcohol ingestion to concentration. The similarity between the functions reported by Everett \& King (1970) and those of the present study occurred despite the presence of a major procedural difference and across a wide range of alcohol concentrations.

Everett and King employed a session length of $100 \mathrm{~min}$, as did the present study, but they delivered the food pellets according to a variable time schedule, while the present study employed a fixed time schedule. Furthermore, the Everett and King study manipulated alcohol concentration values of $1 \%, 2 \%, 3 \%$, $4 \%$, and $5 \%$, whereas the present study used concentrations of $2.5 \%, 5 \%$, $7.5 \%$, and $10 \%$. The similarities in the shape of the functions reported by these two studies indicate the general influence of concentration as a variable influencing schedule-induced alcohol drinking.

Lester (1961) reported his rats as consuming $1.7 \mathrm{~g}$ of absolute alcohol during 180-min sessions when they were obtaining food pellets programmed on a VI 1-min schedule and drinking a $5.6 \%(\mathrm{w} / \mathrm{v})$ alcohol solution. Lester further maintained that drinking and the attendant absolute alcohol ingestion decreased dramatically to a level of approximately $.3 \mathrm{~g}$ of absolute alcohol per session when the pellets were delivered freely on a periodic basis.

The results reported by Everett \& King (1970), Hawkins et al (1970), and the present study confirm Lester's (1961) finding that rats receiving spaced food pellets consume large amounts of absolute alcohol during relatively short periods of time. The results of these studies did not, however, confirm Lester's (1961) finding of reduced alcohol consumption with periodic or nonresponse-contingent schedules.

Everett \& King (1970) reported absolute alcohol values ranging from 1.0 to $1.69 \mathrm{~g}$ per session when alcohol concentrations ranged from $2 \%$ to $5 \%$. Using a procedure which delivered 100 pellets per session according to a FT 1-min schedule, Hawkins et al (1970) reported absolute alcohol consumption of approximately $1.3 \mathrm{~g}$ per session with a $5 \%$ (v/v) concentration. Additionally, the present study found absolute alcohol intake ranging from 1.0 to $1.5 \mathrm{~g}$ per session, with concentration values ranging from $2.5 \%$ to $10 \%(\mathrm{v} / \mathrm{v})$. The procedure used in this study was the same as that employed by Hawkins et al (1970).

The results of these studies indicate that high levels of "voluntary" alcohol consumption can be maintained by VI, VT, or FT 1-min schedules across alcohol concentrations ranging from $2 \%$ to $10 \%$

\section{REFERENCES}

P. B.. \& KING, R. A. Plcohol ingestion. Psychonomic Science, 1970, 18, 278-279. FALK, J. L. Conditions producing psychogenic polydipsia in animals. Annals of the New York Academy of Sciences, 1969, 157, 569-593.

HAWKINS. T. D.. EVERETT, P. B., GITHENS, S. H., \& SCHROT, J. F. Adjunctive drinking: A functional analysis of water and alcohol ingestion. In schedule-induced and schedule dependent phenomena. Vol. 1. Toronto: Addiction Research Foundation, 1970. Pp. 227-285.

LESTER, D. Self-maintenance of intoxication in the rat. Quarterly Joumal of Studies on Alcohol, 1961, 22. 223-231. 